testicular function in the rat. The other four papers in this section are concerned with the endocrinology of female domestic mammals, wstrogen metabolism in the human foetus and new-born, the transplacental passage of steroid hormones and a paper on the metabolic effects of progesterone in man.

The largest single portion of the volume is devoted to six papers on hormones and electrolytes. The subjects covered include: mechanisms regulating the control of aldosterone, mechanisms of œdema formation, primary aldosteronism, the physiology of the posterior pituitary and its effects on permeability of membranes, etc.

The volume concludes with two papers on the regulation of glucose uptake by rat heart muscle and the effect of insulin and other hormones on the isolated perfused rat liver.

This volume maintains the high'scientific standard set by the sixtcen previous issues and contains a series of informative chapters by experts in diverse areas of hormone research. Like its predecessors this volume contains an "edited discussion" after each communication. Conferences require discussion, but the value to the reader of the inclusion of discussion in the published text might be reviewed by the organizers or the editorial axe could be used advantageously here and there.

Tho book is well produced and illustrated and this series is now an obligatory annual reference book for all endocrin. ologists; in addition, this volume will appeal to many other biologists.

G. S. BOYD

\section{PAPER SCIENCE}

\section{Formation and Structure of Paper}

Transactions of the Symposium held at Oxford, Septem. ber, 1961. Edited by Francis Bolam. Vol. 1 : pp. $\mathrm{x}+535+$ xliv +34 plates. Vol. 2 : pp. viii $+536-910+$ xliv. (London: Technical Section of the British Paper and Board Makers Association (Inc.), 1962.) £10 10s.

GOR the first twenty-five years after its foundation in 1920 the Technical Section of the British Paper and Board Makers' Association depended, for its publications, on the research efforts of very few men. For a long time there was only one qualified worker in the whole British paper industry and many technical papers were written by busy routine workers in their spare time. Some indeed were officially discouraged from attending meetings of the Technical Section in case they 'gave anything away'. By the end of the First World War the climate of opinion was changing. The British Paper and Board Industry Research Association was established at Kenley and several of the larger companies set up research laboratories.

An international conference on paper technology was successfully convoned in Paris in 1955 by the French organization 'L'ATIPE' and increasing numbers of British technologists were able to attend similar meetings in the United States. The fundamental research committee of the Technical Section arranged a successful symposium in Cambridge in 1957 and its proceedings were later published as Fundamentals of Papermaking Fibres, edited by F. Bolam, Technical Section, 1958. At the conclusion of that conference it was decided that another symposium on Formation and Structure should be held in Oxford in 1961 and the two volumes under review are the transactions of this meeting.

At each symposium the contributors came from the United States, Canada, Australia and several European countries as woll as from Great Britain. The Cambridge symposium was to a considerable extent a review of existing knowledge and is very useful to teachers of paper science.

The Oxford symposium, with its subject announced four years ahead, attracted a much larger proportion of new work than the Cambridge meeting and is, probably, of more interest to research workers. In summing up the conference at its conclusion, Prof. Rånby (Stockholm) said, "What has been presented here has, indeed, advanced our knowledge of the structure and basic properties of paper. In particular, I congratulato our British colleagues, who have contributed so beautifully in this field of research, which we previously did not think of as a speciality for this country". The early members of the Technical Section who struggled with what was known, most incorrectly, as "Paper Chemistry" with desperately little equipment and negligible library facilities might foel indeed that "the wheel is come full circle".

Paper is a porous assemblage of fibres, and it is difficult to describe its properties in precise scientific terms. Even its thickness is indeterminate; the value measured depends so much on the pressure used in the micrometer that it is best to avoid quantities like stress which necessitate the use of thickness in calculation. There are numerous empirical physical and chemical tests well user in commercial specifications.

The papers given at the Oxford symposium are a note. worthy attempt to viow paper in more fundamental terms than usual. Corto and Kallmes have shown that many properties can be explained by the statistical geometry of random straight lines. For studying the permeation of fluids a paper may be considered to be built up from very thin networks which are themselves com. posed of random polygons built from these straight lines. There are many excellent photomicrographs of the surface structure of paper from Kenley, electron micrographs of different parts of fibres from Darmstadt and photographs of paper made with the scanning electron microscope in Montreal. Page and Tydeman (Konley) develop a theory to explain the anisotropic tensile and hygro-expansive properties of paper in terms of structure and show in particular that the compressive forces which occur in drying can cause fibres to contract longitudinally. and frequently to exhibit micropuckering. This is confirmed by electron micrographs from Montreal introduced into the proceedings after the conference.

The early Chinese paper-makers discovered that paper could be made from vegetable fibres by suspending them in water and drying them without any other adhesive, but the reasons for the adhesion are still debated. The current hydrogen bonding theory and visco-elastic properties related to it are developed by Nissan. Bonds between fibres can be seen to break (Page) and heard to break (Corte) while the stresses within fibre joints can bi treated and elarified mathematically (Van den Akker). There still seems to be some discrepancy between the views of paper scientists and colloid chemists as regards the distance over which bonding forces can aet.

A simple but ingenious method for breaking up paper and analysing the clay-fibre ratios at different levels through its thickness is described by Groen. Investigations on uniformity, flocculation and wet end variables are described by Robertson and Mason and by Wrist. Only a few of the many interesting papers ean be mentioned here; in the two volumes there is plenty of mathematies and physies, some morphology and scarcely any chemis. try. Ranby's summary and Rance's introduction are t.wo of the most valuable ehapters and should be read first.

The issue of the main papers as preprints before the conference gave rise to lengthy discussions which are reported in full. A number of contributors succeeded in introducing sizeable papers at this stage. This, and the lack of brevity of some authors, mentioned in Ranby's summary may account, in part, for the high cost of the book. Some of this must, however, be due to the numerous micrographs which are exceptionally well reproduced.

It is difficult to see how more information on structure could have been collected in the present state of knowledge even though some might, perhaps, have been left out. It is expected that the book will sell well all over the world to those interested in advancing the subject of paper science.

F. LyTh Hunson 